Vol.15, No. 56, July, 2020, 904-915

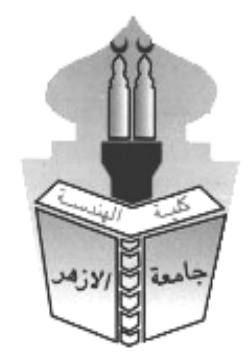

\title{
ANALYTIC STUDY FOR THE IMPORTANT SYSTEMS AND APPLICATIONS FOR CONVERTING GATED COMMUNITIES INTO SMART COMMUNITIES
}

\author{
Ayman Hamza Thabet ${ }^{*}$, and Abeer M. Galal Eldeen \\ Architecture \& Housing Research Institute, Housing \& Building International, Research \\ Center, Dokki, Giza,.Egypt \\ *Corresponding Author E-mail: aymanhmza@yahoo.com
}

\begin{abstract}
Egypt was influenced by the global technological development, especially in cities planning, The research studies converting the gated communities into smart communities, that use information technology to provide services to their inhabitants, by using the inductive approach in which the research relied on studying and extracting the advantages of gated communities that make them applicable, in addition to studying different smart systems and applications that can be applied in buildings and urban spaces in gated communities. Second: The applied method in which the research relied on (questionnaire) for some Egyptian real estate development companies, as well as the opinions of gated communities residents, followed by an analytical study of the results of the questionnaire to conclude the most important smart systems and applications with priority that can be applied and activated in gated communities.
\end{abstract}

\section{KEYWORDS: Smart Communities, Gated Communities, Real estate, Smart Systems, and Smart Application}

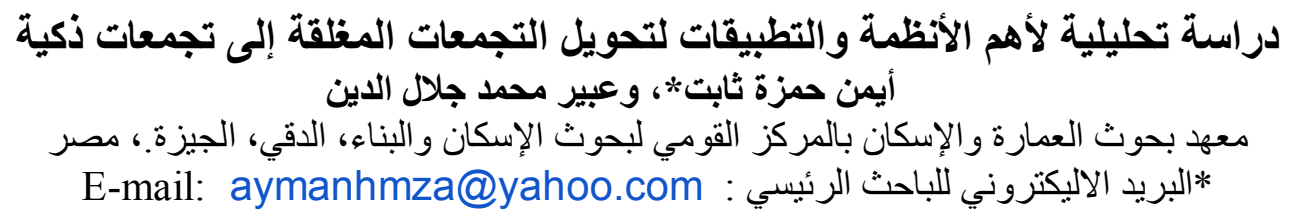

تأثرت مصر بالتطور التكنولوجي العالمي خاصة في مجال تخطيط المدن، حيث بدأت في وضع خطط للبدء في تتفيذ بعض

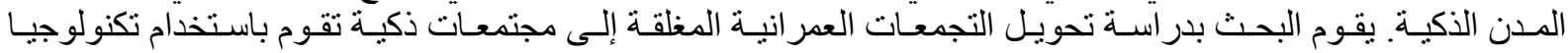

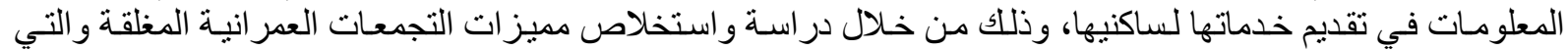

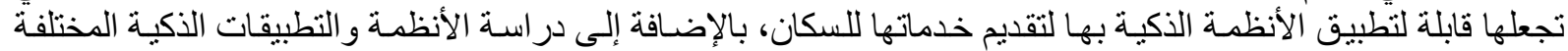

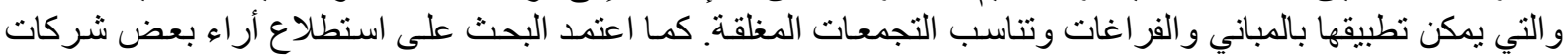

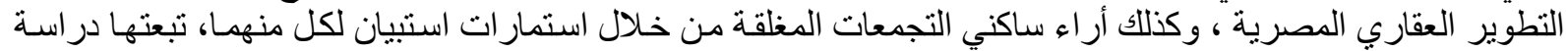

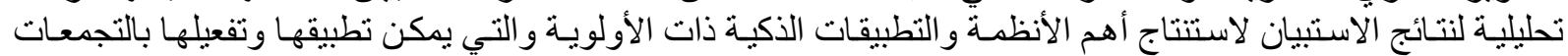
المغلقة. الكلمات المفتاحية : تجمعات ذكية، تجمعات مغلقة ، مطور عقاري، أنظمة ذكية، وتطبيقات ذكية السريع لأجهزة الحاسوب و البرمجيات إلى الاعتماد بشكل أساسي على التطبيقات في الأنشطة الخدمبـة والتجاريـة ووسيائل 
النقل و المو اصلات، مما سـاعد في تحسين مستوى الخدمات و إنجاز ها في أقل وقت ممكن، بالإضـافة إلى تطبيق الحلول

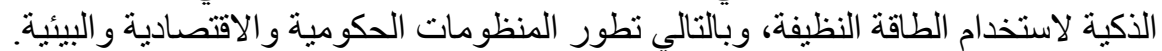

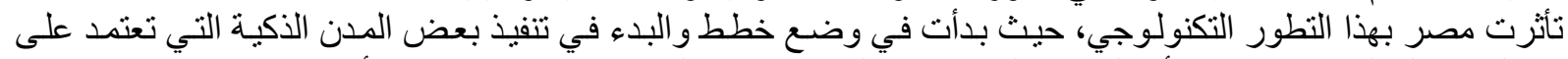

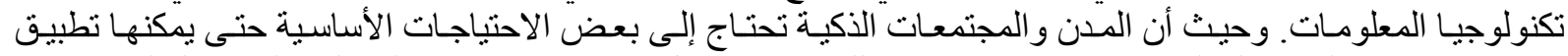

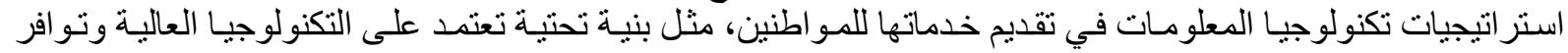

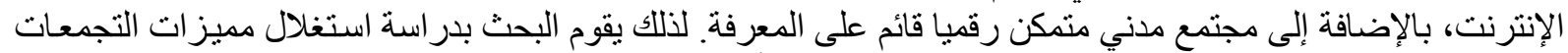

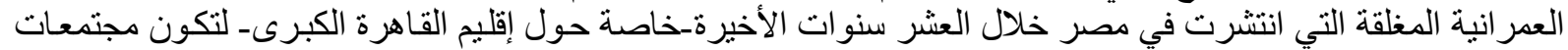
ذكية تقوم باستخدام تكنولوجيا المعلومات في تقديم خدماتها و أنشطتها لساكنيها.

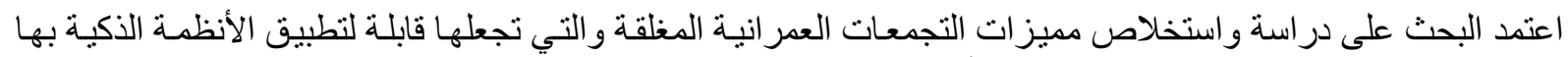

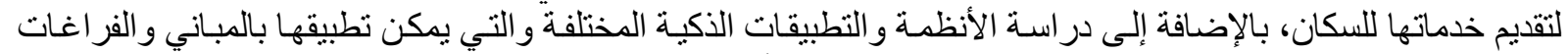

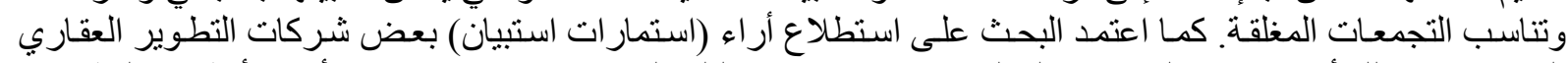

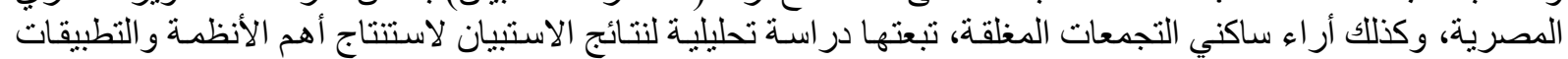
الذكية ذات الأولوية و التي يمكن تطبيقها وتفعيلها بالتجمعات المغلقة.

الهـف: يهدف البحث إلى الوصول إلى أولويـات تطبيق وتفعيل الأنظمـة والتطبيقـات الذكية (المعتمدة على استخدام

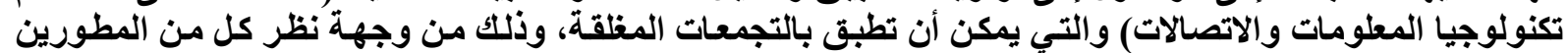
العقاريين والمستخدمين من السكان.

\section{1 - مميزات التجمعات العمرانية المغلقة}

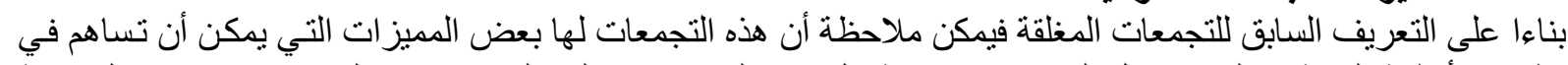

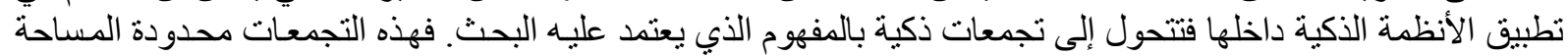

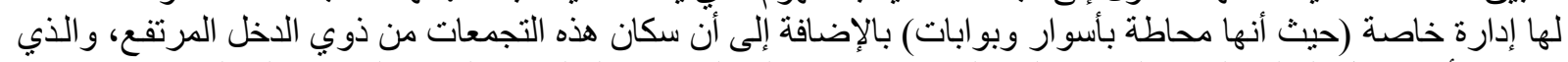

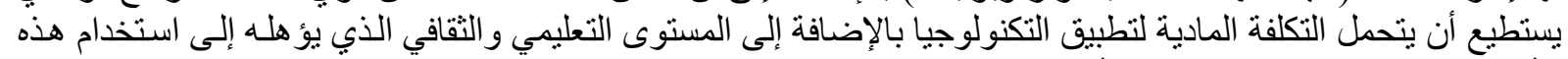

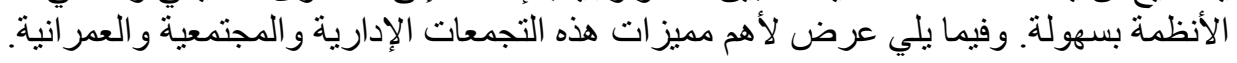

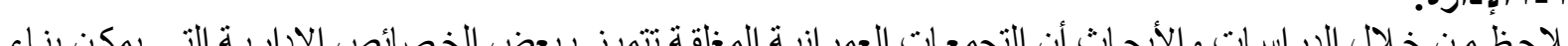

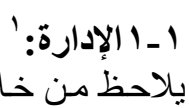

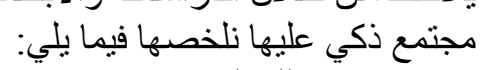

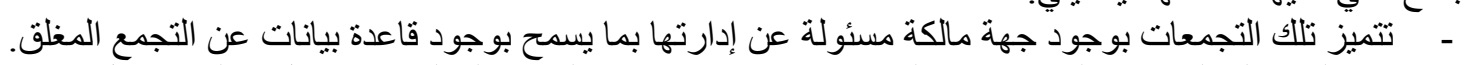

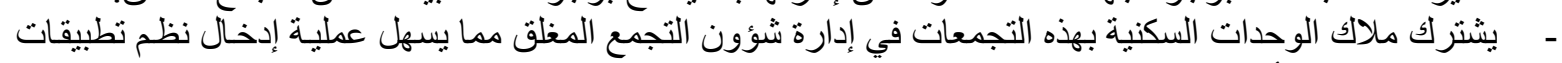

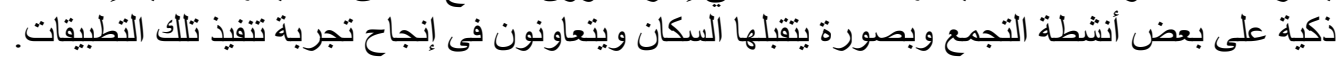

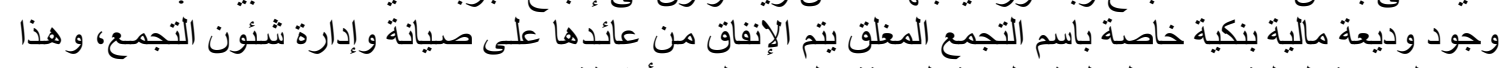

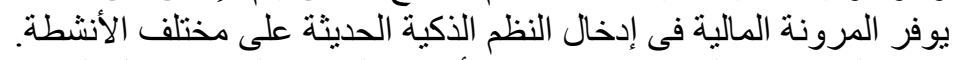

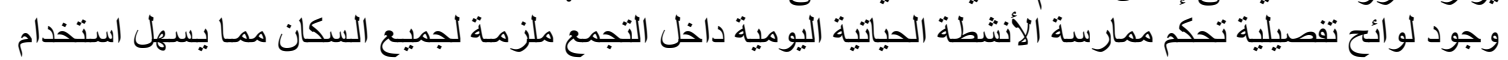

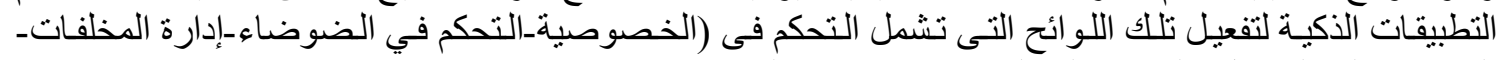

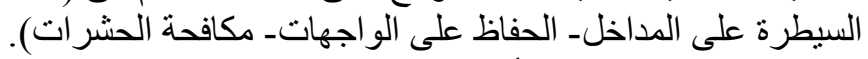

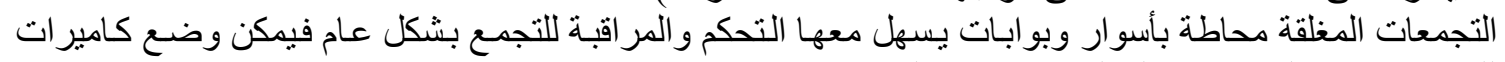

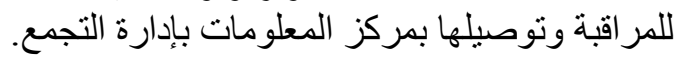

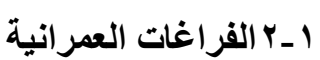
يعتبر تنوع الفر اغات العمر انية من أهم مميزات التجمعات التهات العمر انية المغلقة، حيث يمكن تفعيل التكنولوجيا الذكية و الرقمية

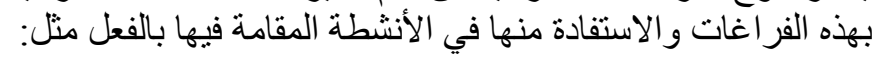

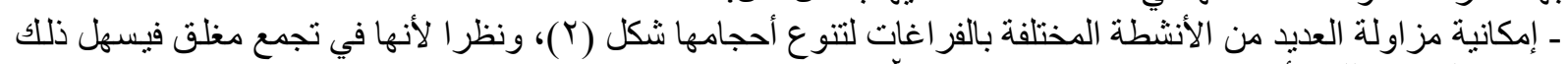
إمكانية التحكم بتلك الأنشطة ببر الأنج وتطبيقات ذكية. 


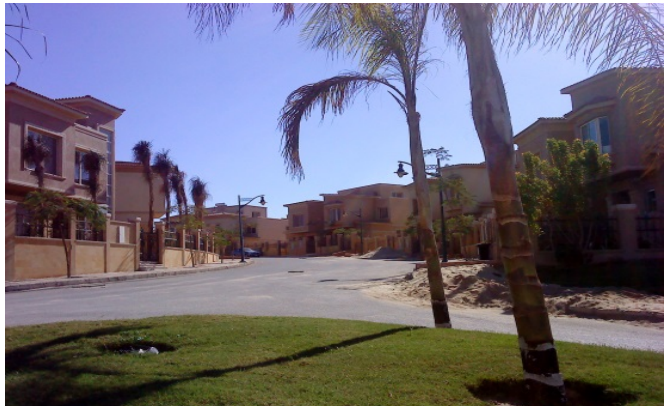

شكل (r) مسارات داخلية يمكن فصل حركة السيارات عنها

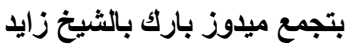

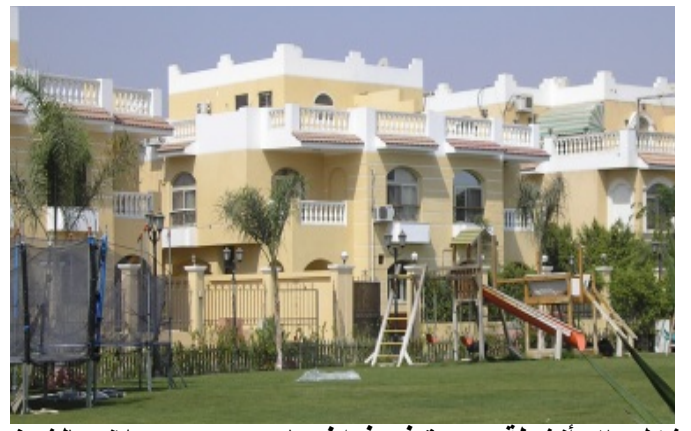

شكل (Y) أنشطة متعددة في فراغ عام بتجمع مون لاند بالشيخ زايد

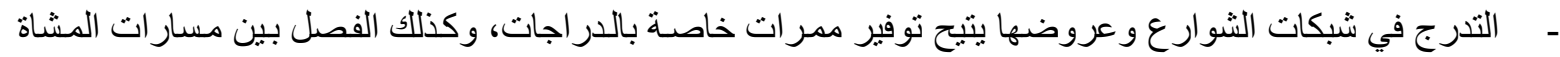

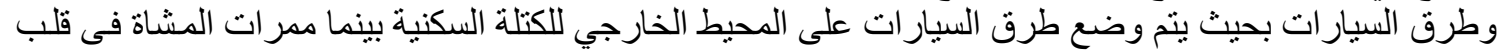

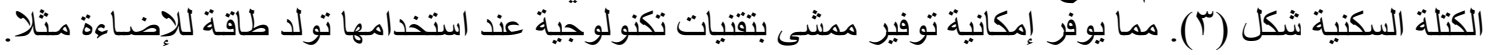

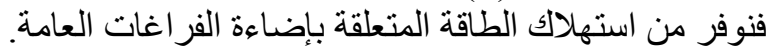

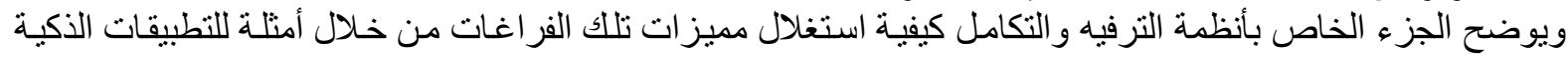

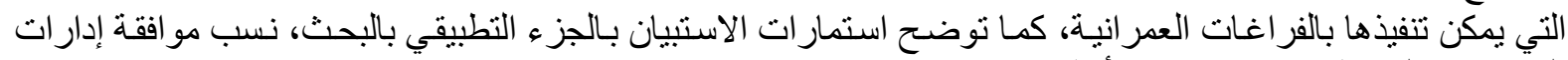
التجمعات علي تطبيق و إدارة هذه الأنظمة.

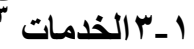

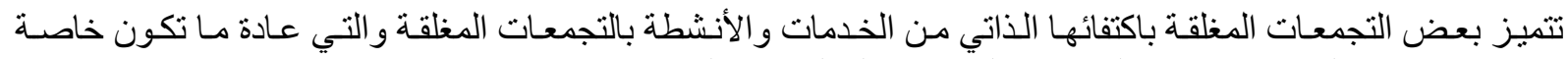

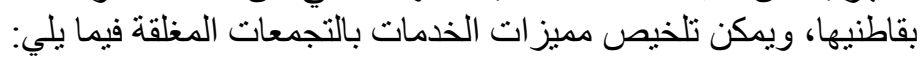

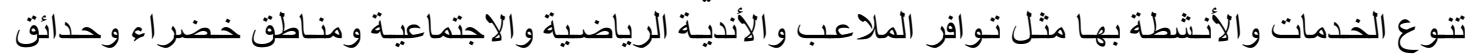

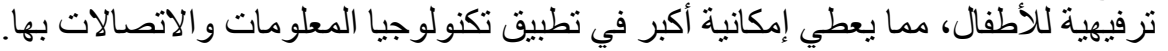

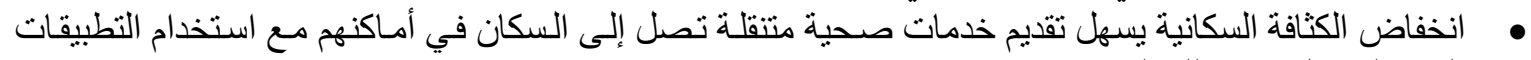
الذكية لتسهيل تقديم تلك الخدمات التهات

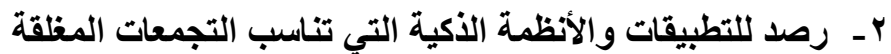

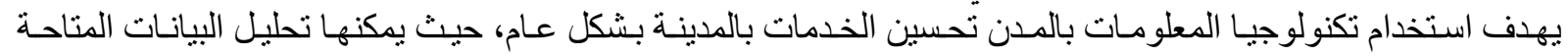

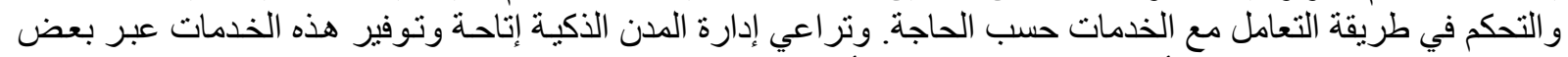

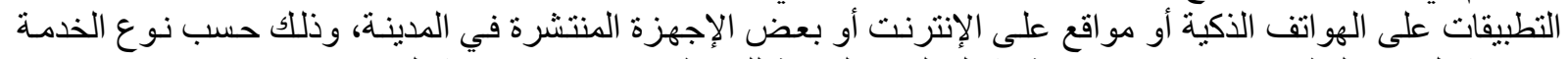

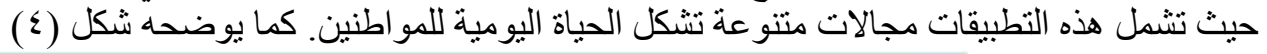

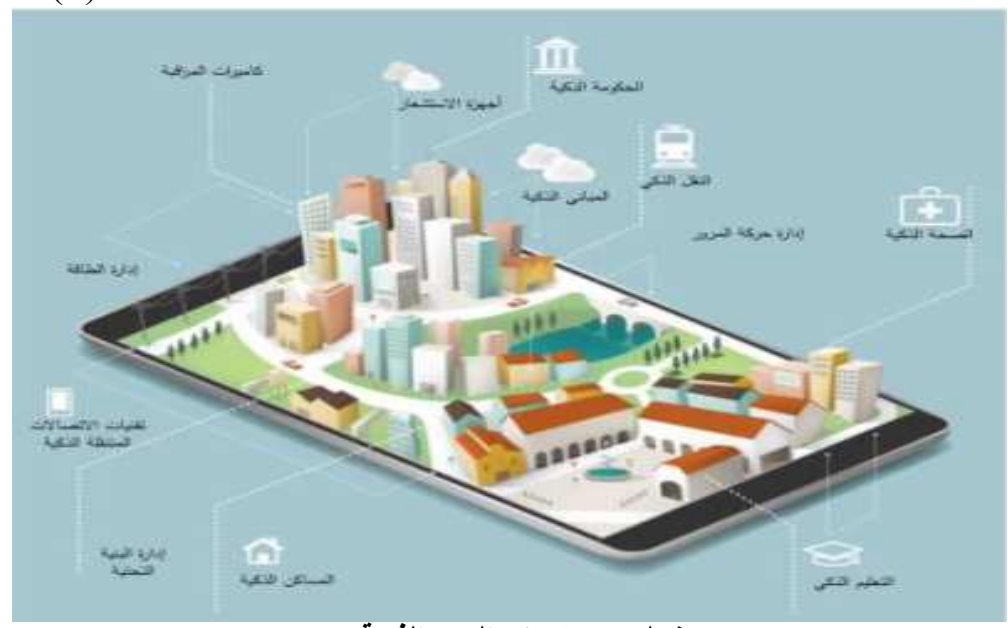

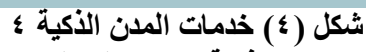

المصدر: ميجا كومار، أكتوبر ه 1 ـ r، بناء مدن ذكية ترتكز على البيانات الذكية، لمحة عامة عن الحل، IMS.

وحيث أن البحث يختص بدر اسة التجمعات المغلقة (والتي تعتبر جزء من المدينة) فطبيعة الحال لا يمكن تطبيق جميع هذه التها الخدمات و التطبيقات الذكية، وقد تم اختيار بعض التطبيقات التي يمكن تطبيقها على مستوى التجمعات المغلقة والمرنبطة 
بالمباني الخدمية و السكنية و الفر اغات عامـة والخدمات) - بالإضـافة إلى تطبيقات ترشيد استهلاك الطاقة و الإنـارة وكذلك نظم جمع المخلفات الصلبة.

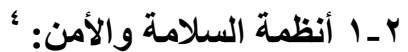

تساعد تللك الأنظمة إدارة الدفاع الديني والحريق وتحقيق الأمن من خلال المر اقبة الإلكترونية للابنية و الفر اغات، نذكر منها

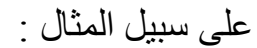

- حساسات الدخان بالفر اغات المعمارية و العمر انية و أنظمة إنذار الحريق الإلكترونية.

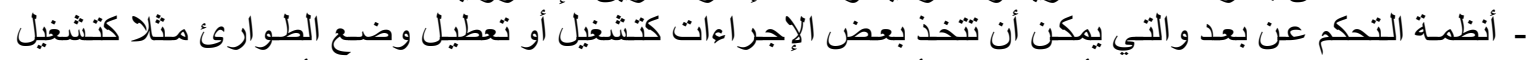

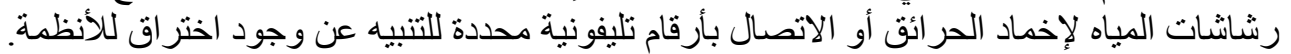

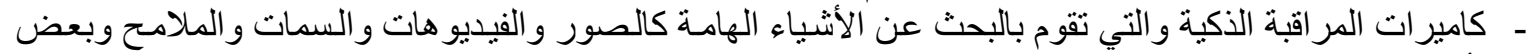

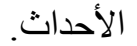

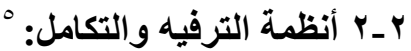

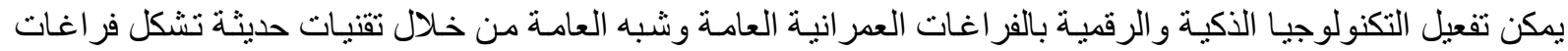

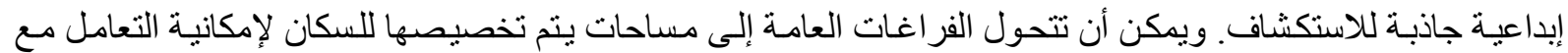

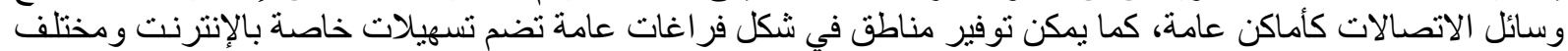

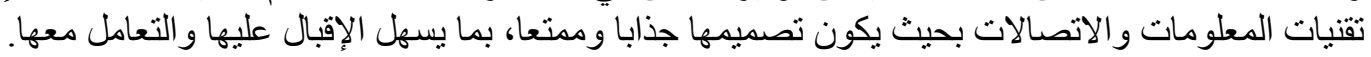

و من أمثلة النطبيقات الذكية التي يمكن تطبيقها في الفر اغات العامة:

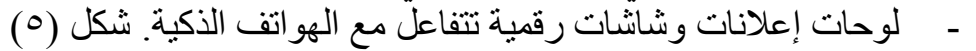

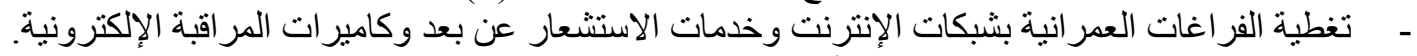

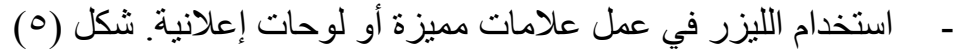

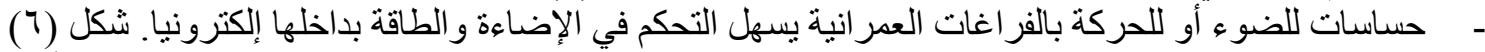

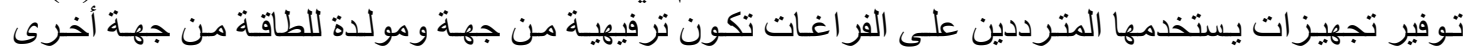

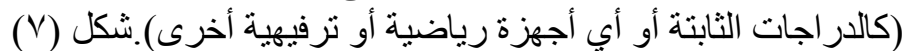

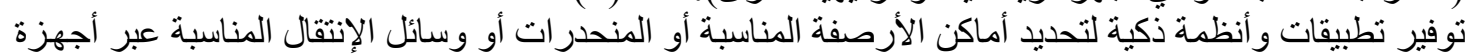

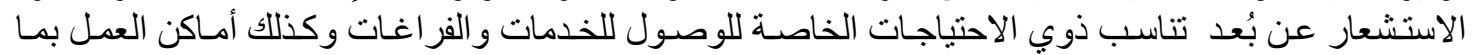

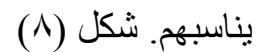
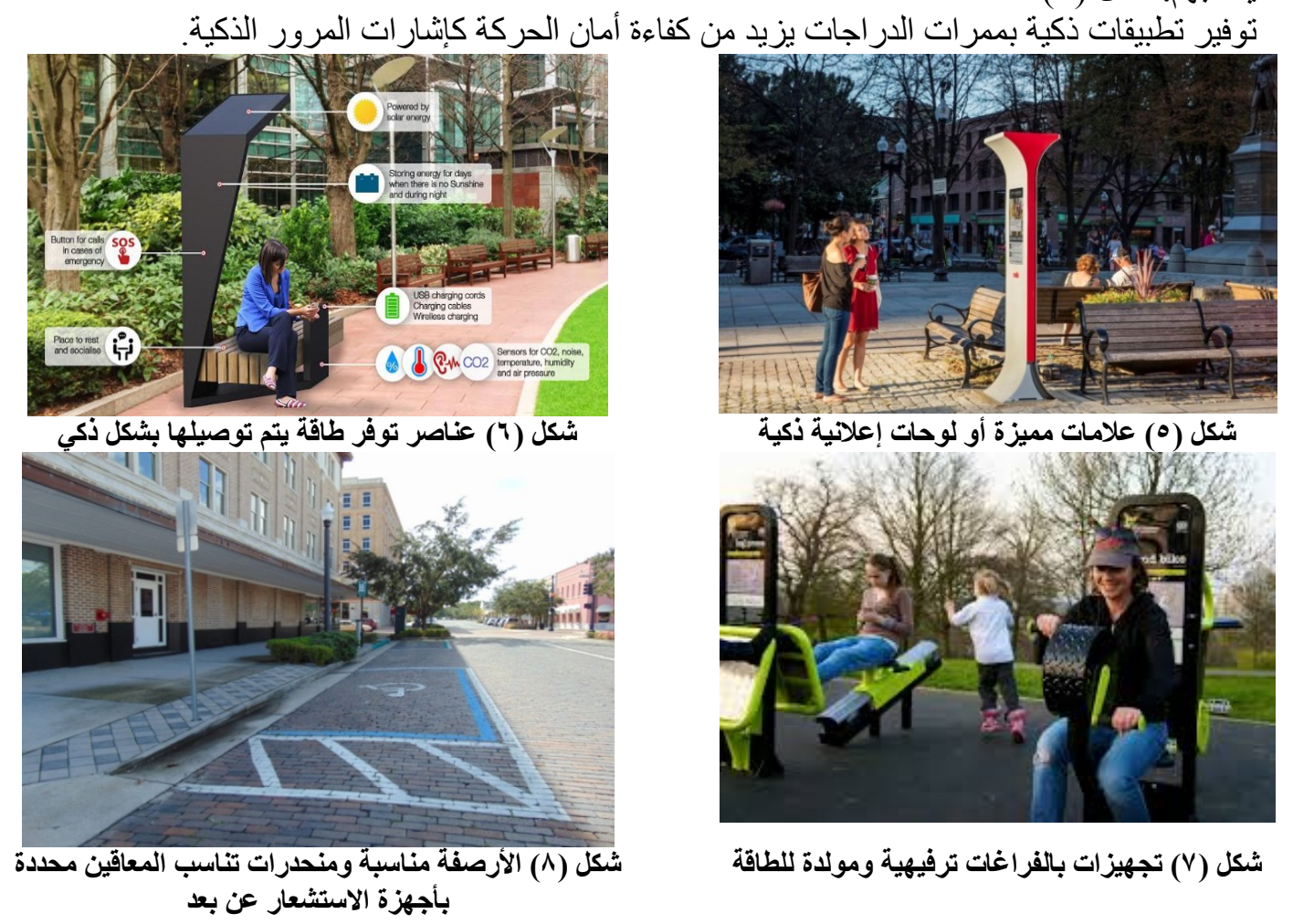

شكل (V) تجهيزات بالفراغات ترفيهية ومولاة للطاقة 


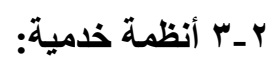

تقلل التطبيقات الخدمية الذكية من الوقت والجهـ المبذول للحصول عليها، حيث اتحاحت إمكانيـة تحريـر الأنشطة الإنسانية

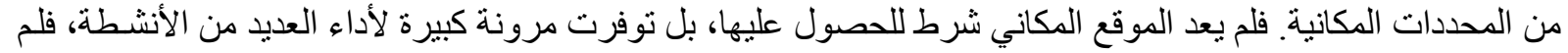

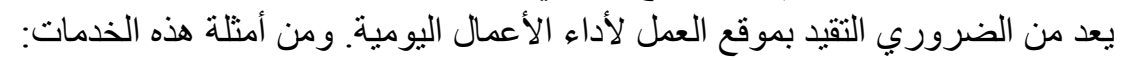

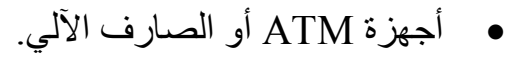

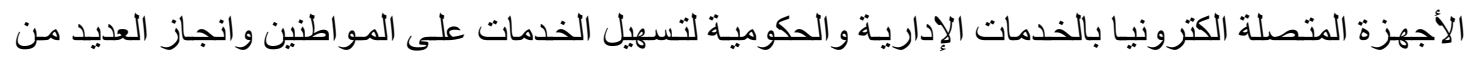

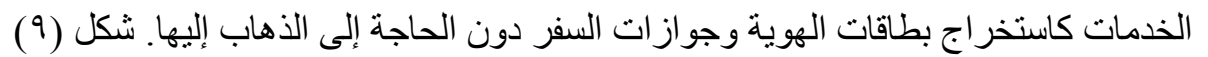

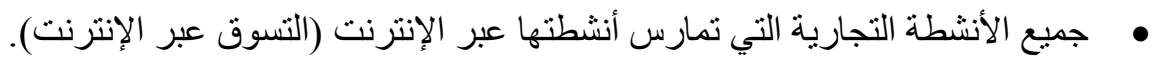

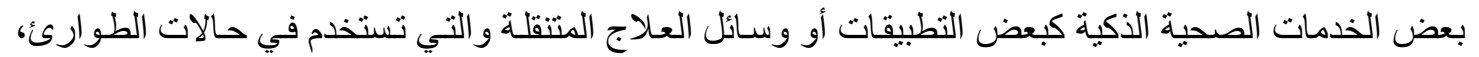

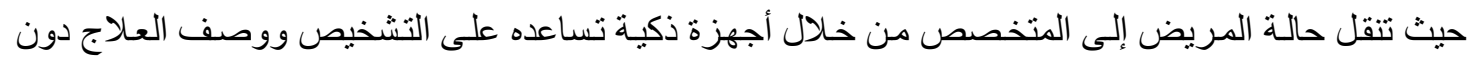

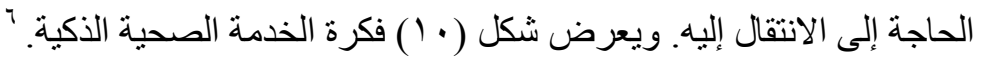

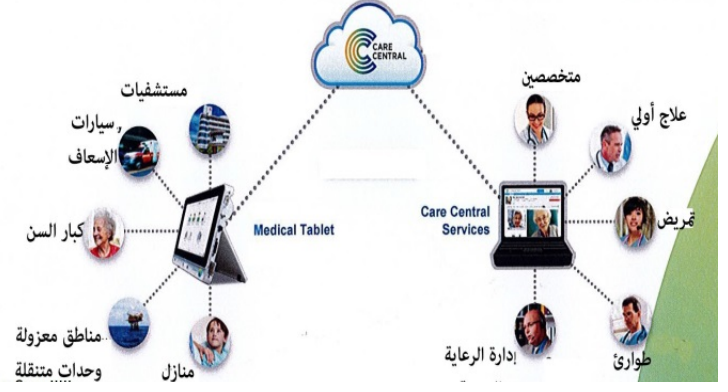

شكل ( • 1 ) فكرة الخدمة الصحية الذكية

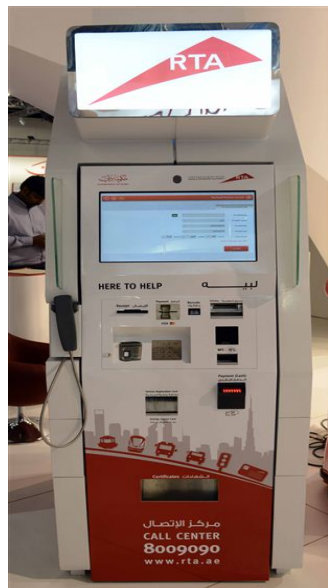

شكل (9) أكثاك ذكية لتجديد رخصة القيادة في دبي

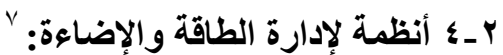

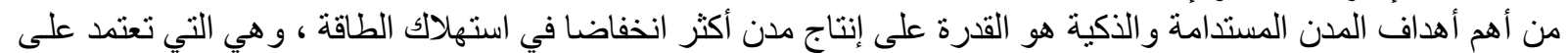

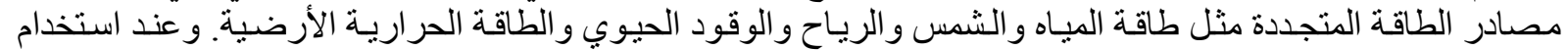

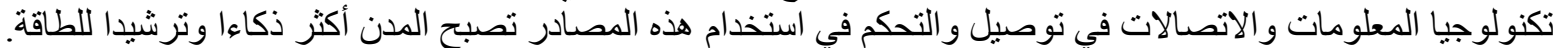

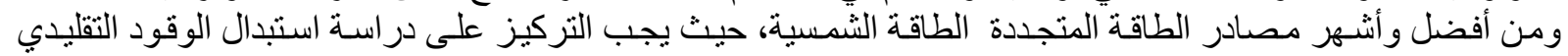

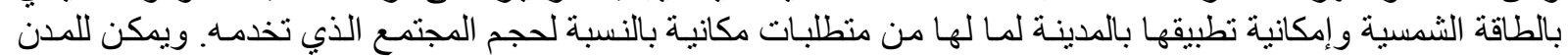
الذكية أن تقوم ببعض النطبية والتبيقات الخاصة بترشيد الطاقة من خلال:

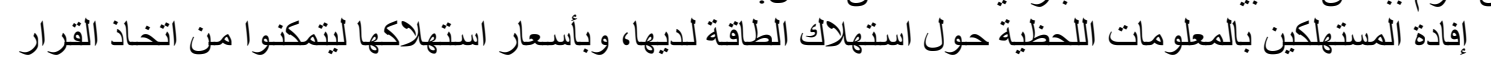

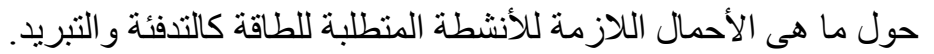

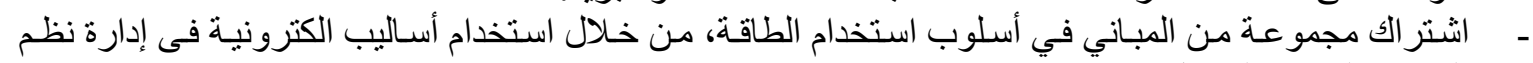

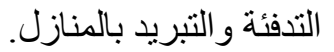

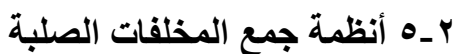

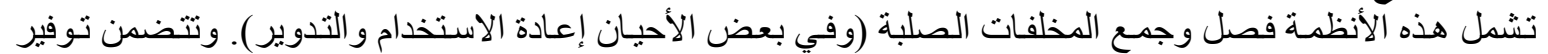

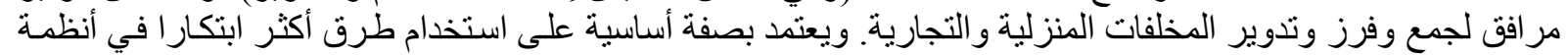

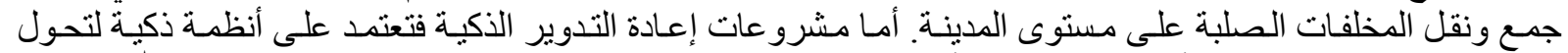

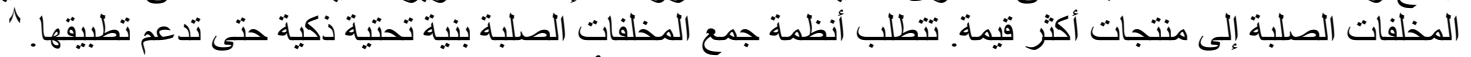

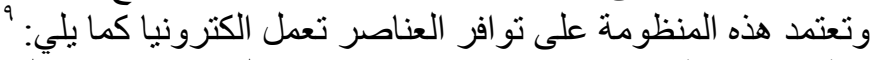

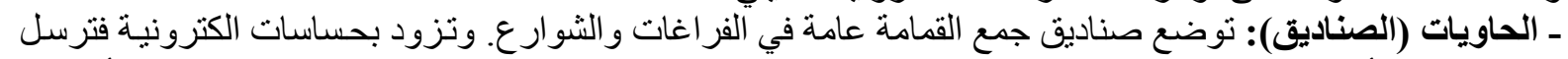

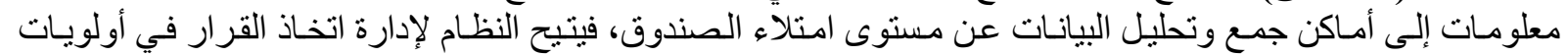
الصناديق المطلوب تفريغها. 
كما يمكن استخدام هذه الصناديق كوسيلة استتمارية للحصول على إير ادات تدخل للتجمع من خلال الإعلانات التسويقية من

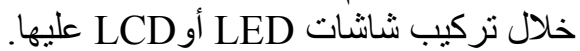

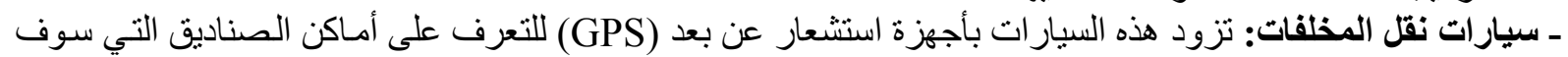

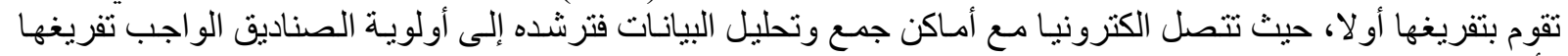
وأماكنها.

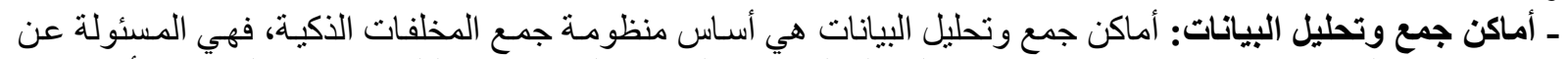

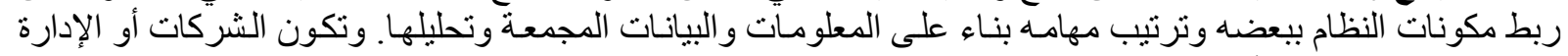
هي المسئولة عن هذه الأماكن.

ب- الاراسة التطبيقية

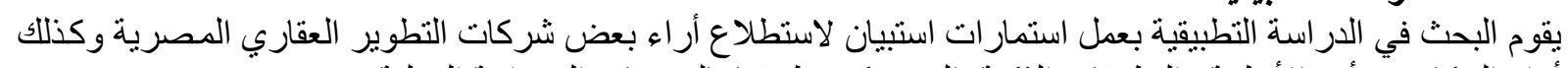

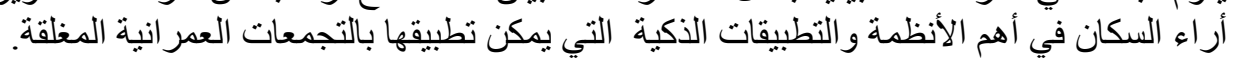

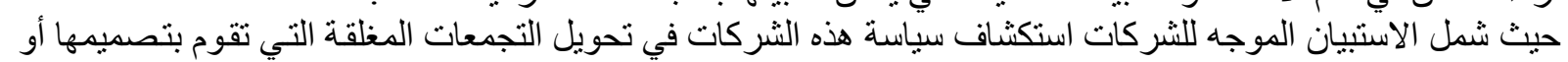

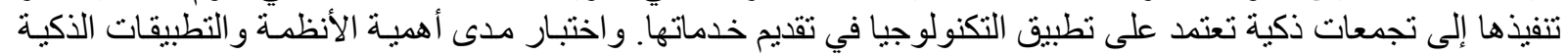

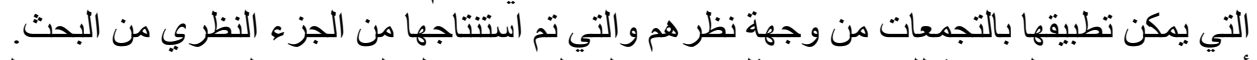

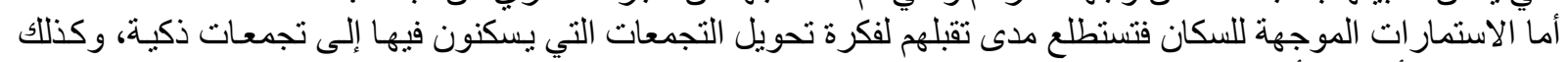

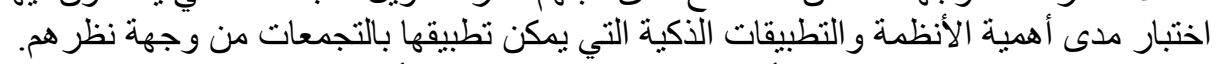

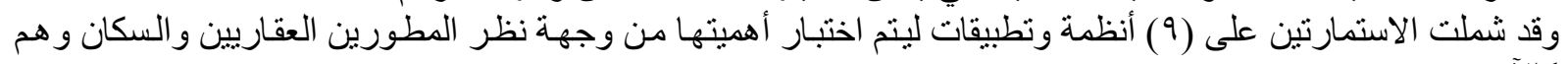
كالآتي:

أي. أنظمة إطفاء حريق بالمباني السكنية والخدمية تعمل الكترونيا ومنصلة بمركز التهر التحكم.

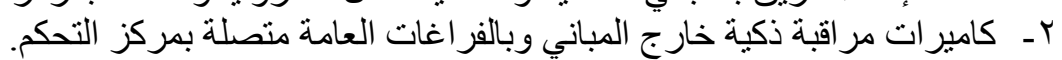

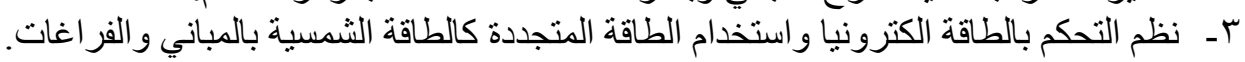
ع - ت تغطية الفر اغات العامة بشبكات الإنترنت

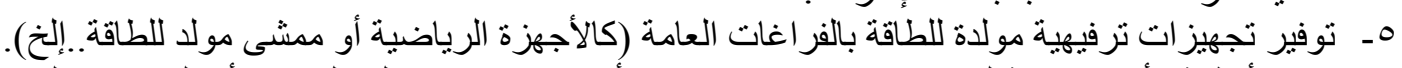

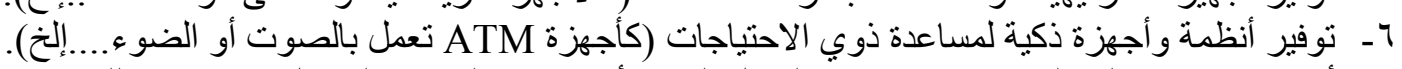

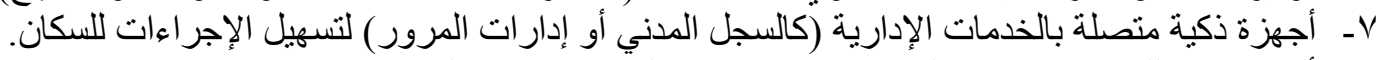

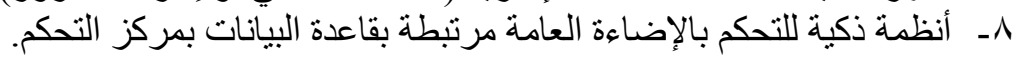

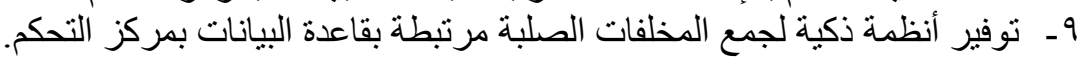

كام البحت بائج الاراسة التطبيقية

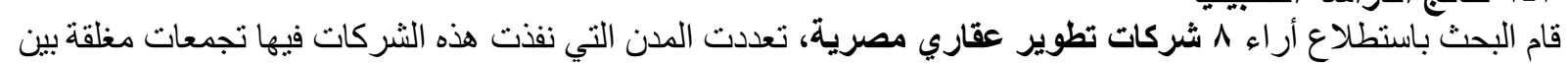

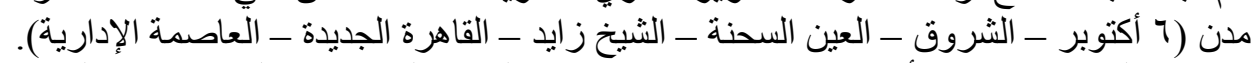

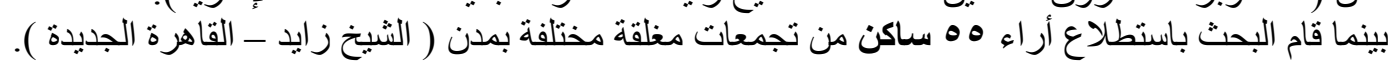
وفيما يلي عرض لنتائج الاستبيانات لكل فئة:

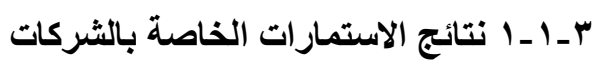

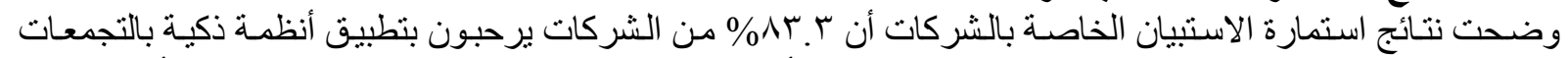

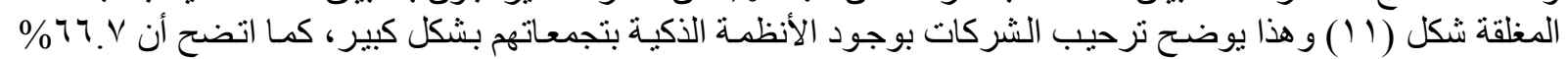

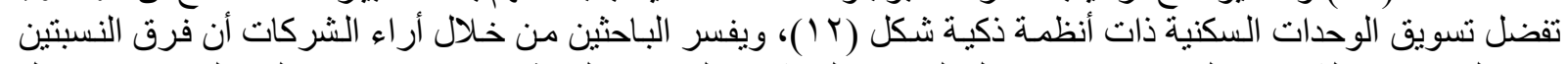

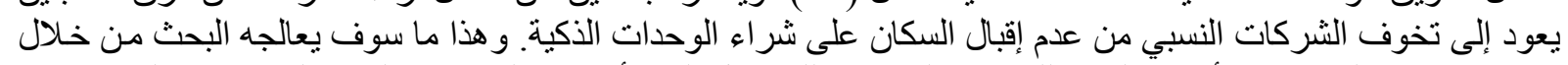

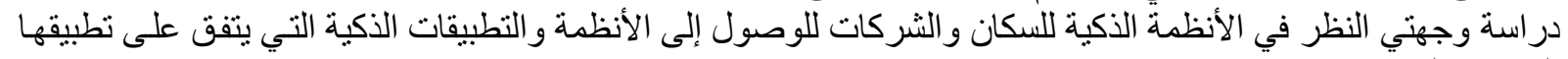

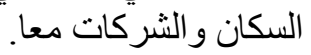



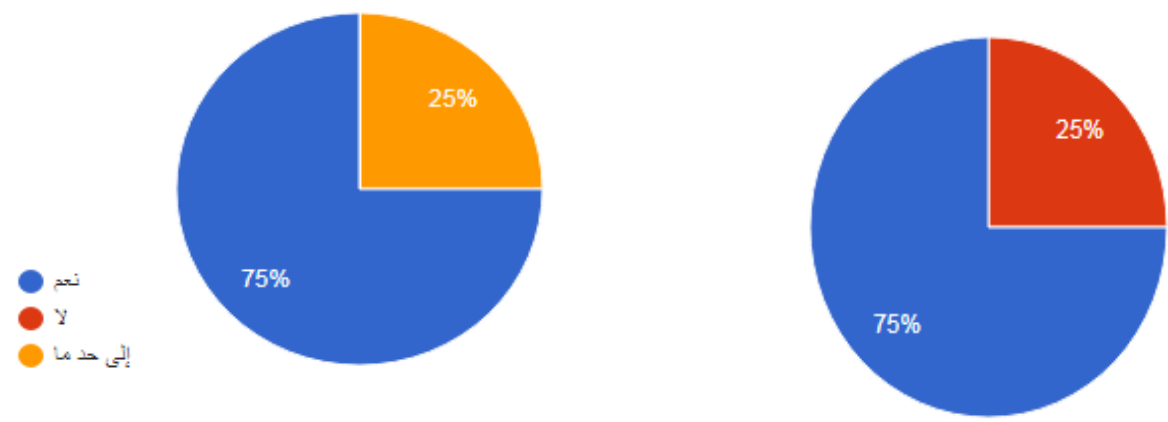

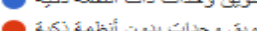

شكل (r 1 ) نسب أفضلية تسويق الوحدات السكنية شكل (1 1 ) نسب ترحيب الشركات بتطبيق الأنظمة الذكية بتجمعاتها

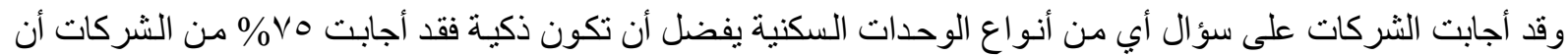

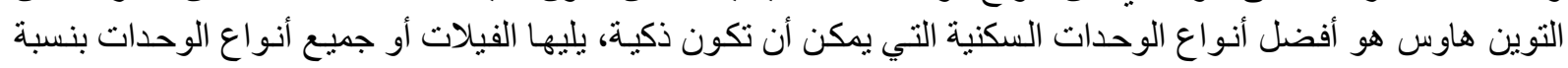
•\% من عينة الشركات شكل (1T).

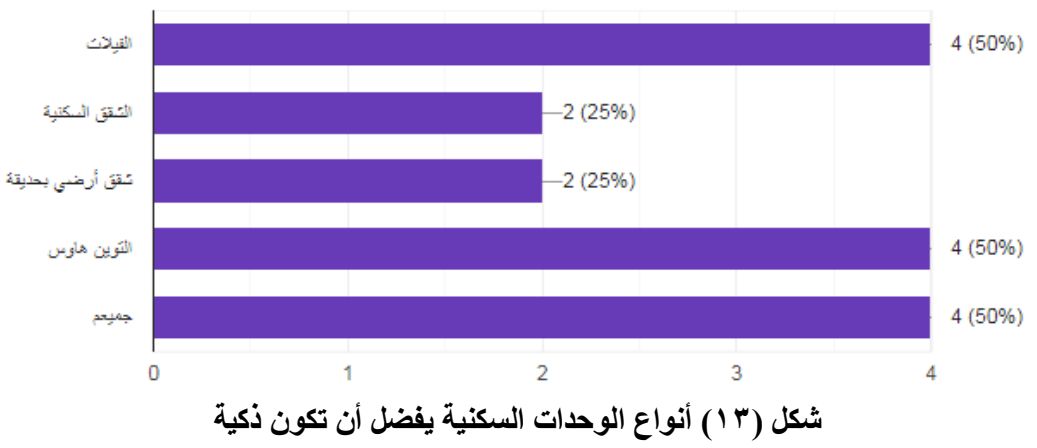

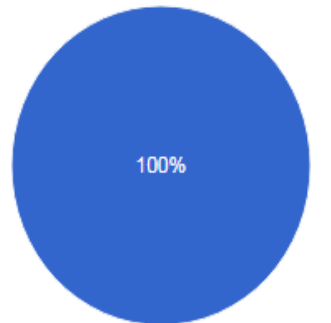
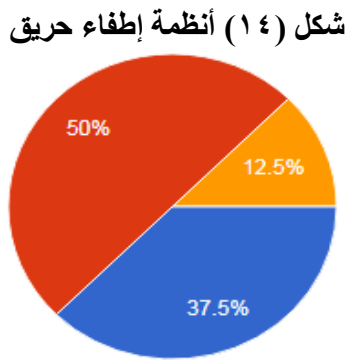

شكل (IV) ت تظطية الفراغات بشبكات الإنترنت
وتوضح الأشكال من (؛ 1 إلى Yr) أهمية الأنظمة والتطبيقات من وجهة نظر الثركات:
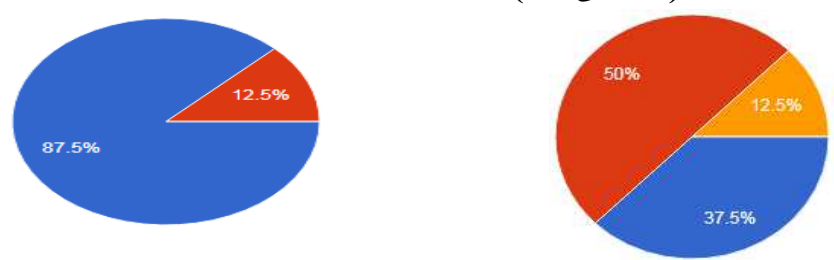

شكل(ه 1 ) كاميرات مراقبة ذكية

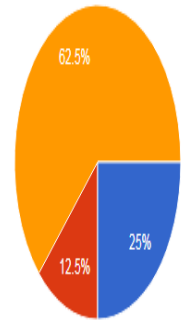

شكل (17 ) نظم التحكم بالطاقة الكترونيا

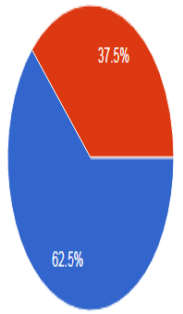

شكل (9 1 ) توفير أنظمة لذوي الإحتياجات 


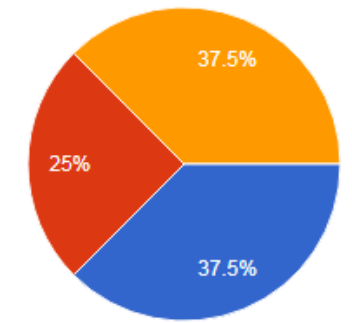

شكل ( • ( ) أجهزة متصلة بالخدمات الإدارية

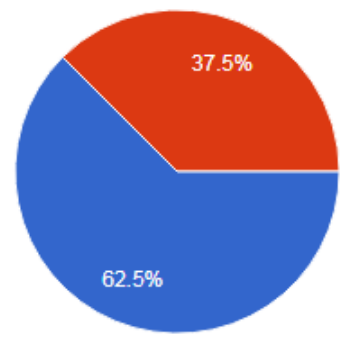

شكل ( ا Y ) أنظمة للتحكم بالإضاعة العامة

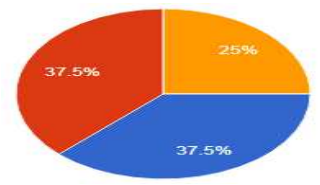

شكل (Yr) توفير أنظمة لجمع المخلفات

الصلبة

مهי

منؤسط الأهبدة

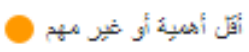

ومن الأشكال السابقة يتضح ما يلي:

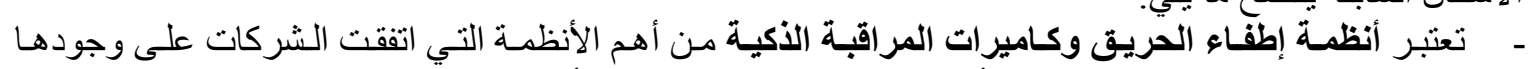

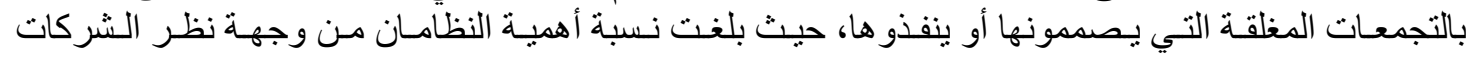

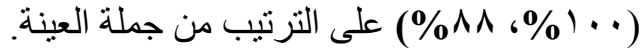

تتساوي نسبة أهمية توفير أنظمة لذوي الذوي الإحتياجات وأنظمة التحكم بالإضاءة العامـة، حيث بلغت نسبة أهميتهما

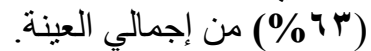

ـ كما تساوت نسبة أهمية كل من نظم التحكم بالطاقة الكترونيا ـ تغطية الفراغات بشبكات الإنترنت ـ أجهزة ذكية

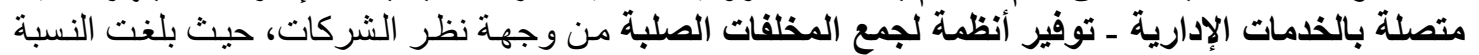

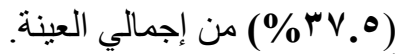

أما توفير تجهيزات مؤلدة للطاقة فكانت من إنظمة النظم الأقل أهمية من وجهة نظر الثركات حيث بلغت نسبة أهمينها (\% \% ro)

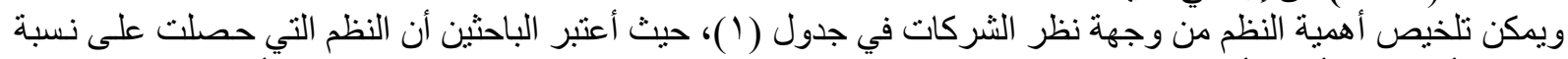

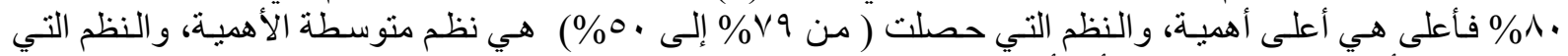
حصلت على أقل من •0\% في نظم أقل أهمية.

جدول (1) أهمية النظم الأكية من وجهة نظر شركات التطوير العقاري

\begin{tabular}{|c|c|}
\hline \multirow{2}{*}{ أعلى أهمية } & أنظمة إطفاء الحريق \\
\hline & وكامير ات المر اقبة الذكية \\
\hline \multirow{2}{*}{ متوسط الأهمية } & توفير أنظمة لذوي الإحتباجات \\
\hline & و أنظمة التحكم بالإضاءة العامة \\
\hline \multirow{5}{*}{ أقل أهمية } & نظم التحكم بالطاقة الكترونيا \\
\hline & تغطية الفر اغات بشبكات الإنترنت \\
\hline & أجهزة ذكية متصلة بالخدمات الإدارية \\
\hline & توفير أنظمة لجمع المخلفات الصلبة \\
\hline & توفير تجهيز ات مولدة للطاقة \\
\hline
\end{tabular}

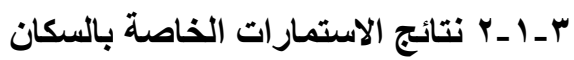

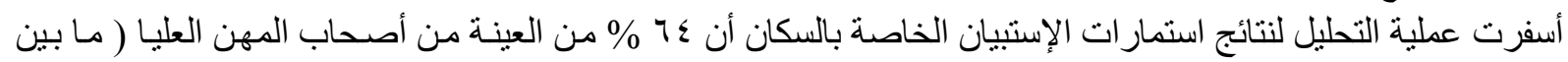

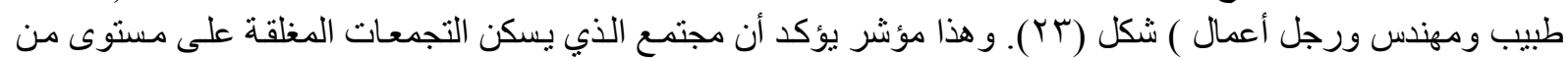

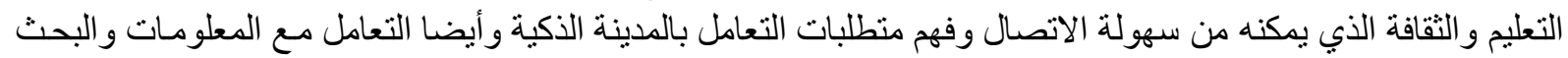
عنها وتحليلها وتقييمها، وذلك يؤكد أن المجتمع من أهم مميز ات التجمعات المغلقة التي تسهل تحويلها إلى تجمعات ذكية. 


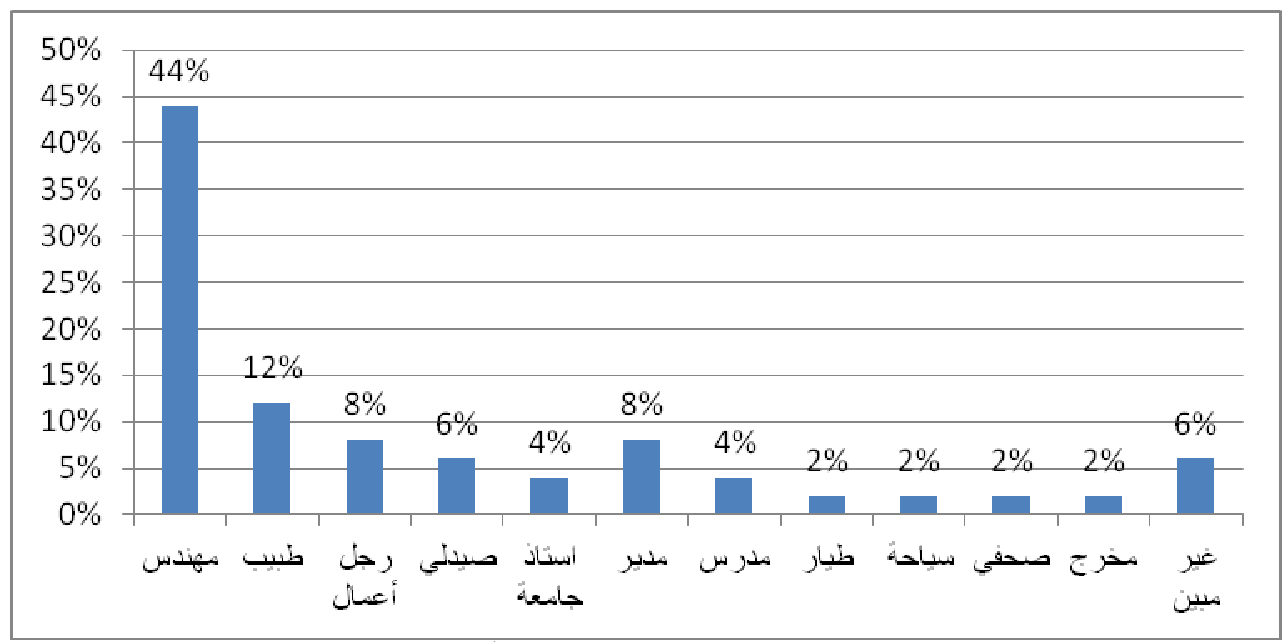

شكل (ب (Y) مهن سكان العينة

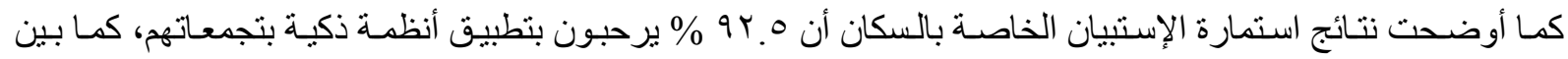

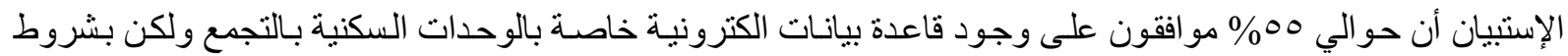

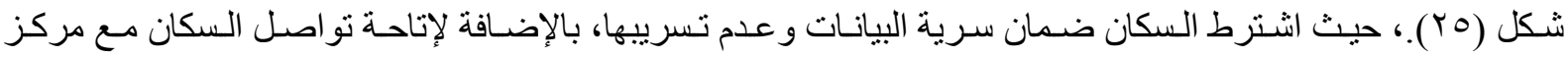

المعلومات بسهولة (ب)،
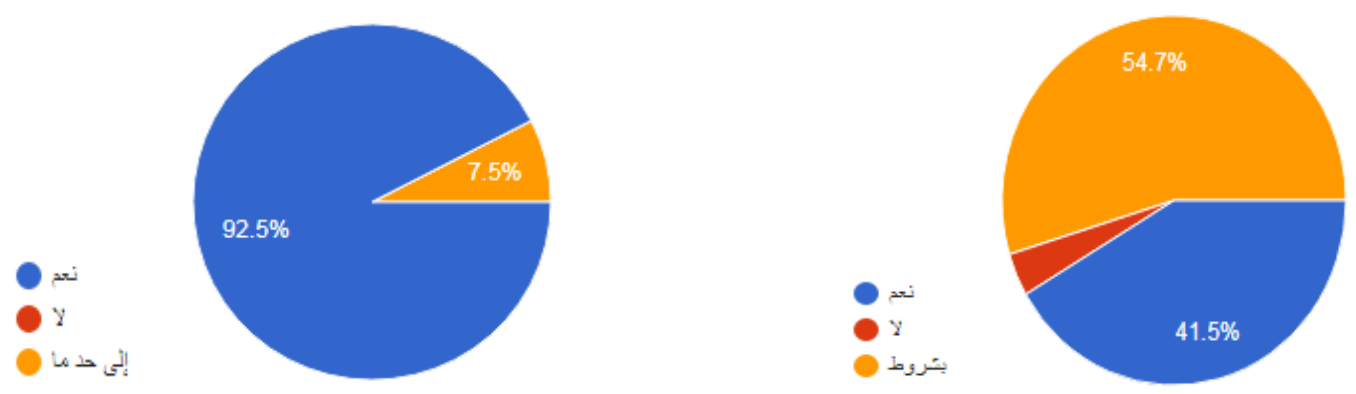

شكل ( ؟ Y) نسب ترحيب السكان بتطبيق الأنظمة الذكية بتجمعاتها

شكل (ro ) نسب موافقة السكان على وجود قاعدة بيانات وتوضح الأشكال من ( ץ إلى ع ) ) أهية الأنظمة والتطبيقات من وجهة نظر السكان:

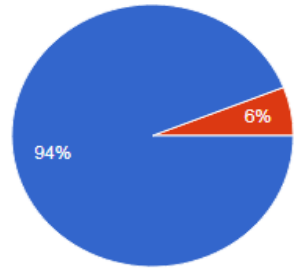

شكل (Y (ץ) أنظمة إطفاء حريق

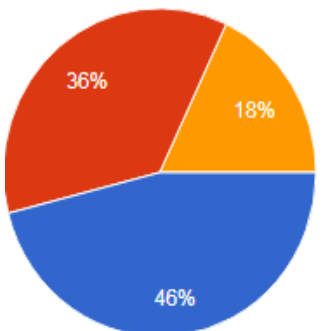

شكل (q ץ) تغطية الفراغات بشبكات الإنترنت

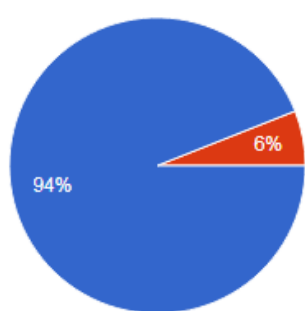

شكل(YV) - كاميرات مراقبة ذكية

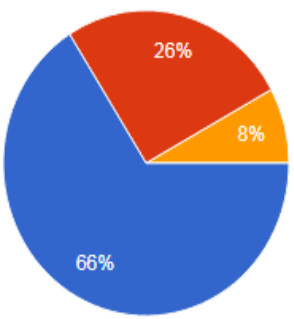

شكل (· · توفير تجهيزات مولدة للطاقة

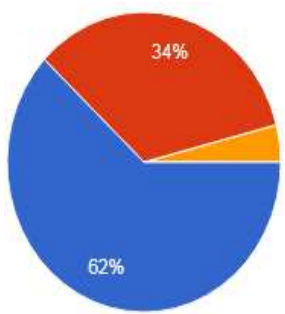

شكل (^^) نظم التحكم بالطاقة الكترونيا

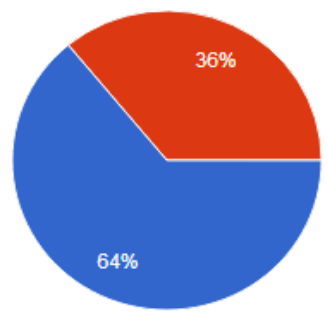

شكل ( آس) توفير أنظمة لذوي الإحتياجات 


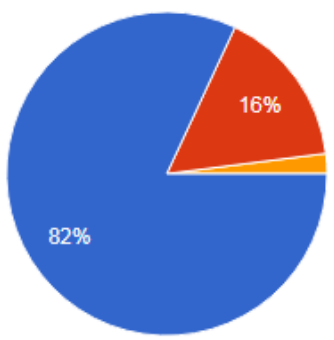

شكل(r آم) أجهزة متصلة بالذدمات الإدارية

عه

مئوسط الأهبنة

p

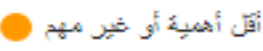

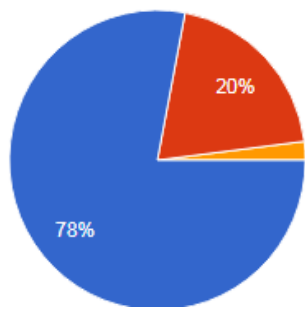

شكل(rr)|أنظمة للتحكم بالإضاعة العامة

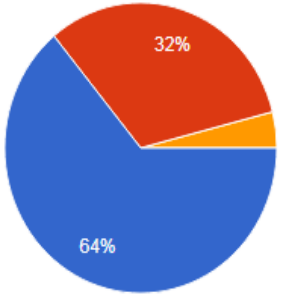

شكل(؟ ؟ ) توفير أنظمة لجمع المخلفات الصلبة

ومن الأشكال السابقة يتضح ما يلي:

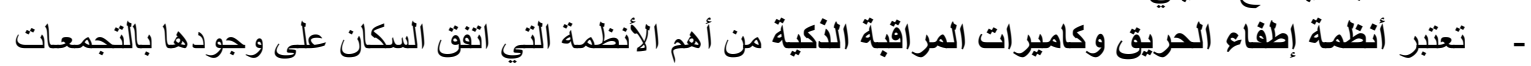

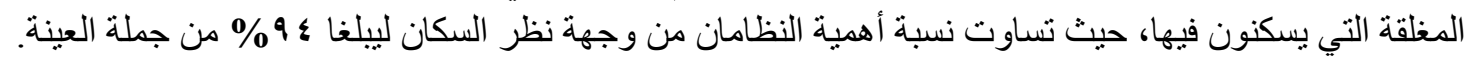

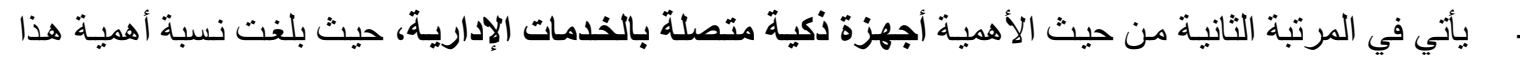

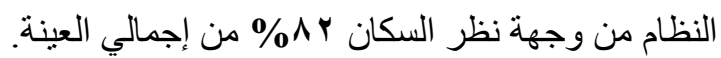

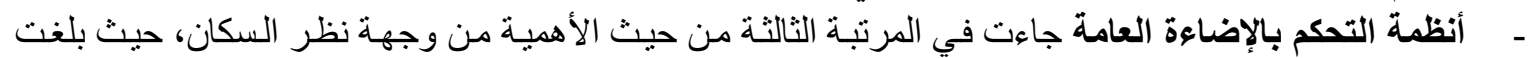

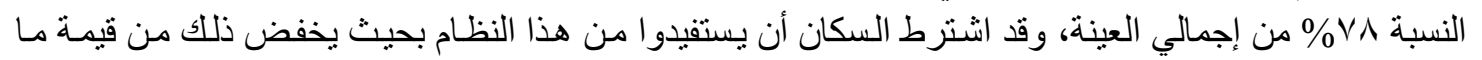

$$
\text { يدفعونه في الصيانة للتجمع. }
$$

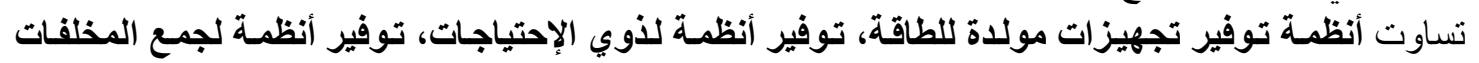

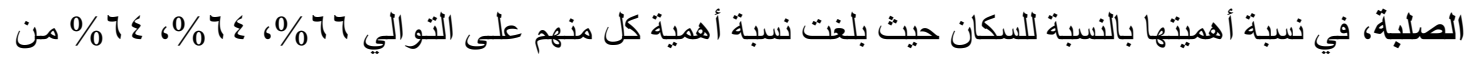

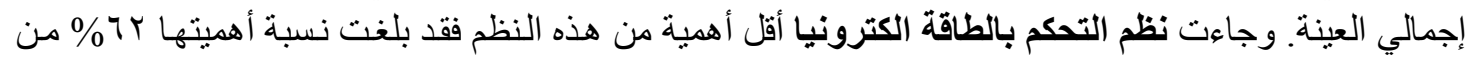

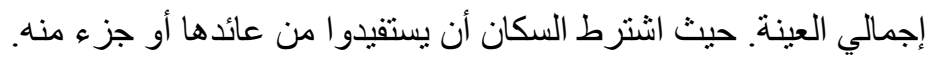

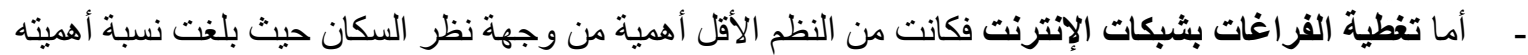

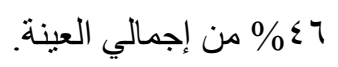

ويمكن تلخيص أهمية النظم من وجهة نظر السكان في جدول (r)، حيث أعتبر الباحثين أن النظم التي حصلت على نسبة

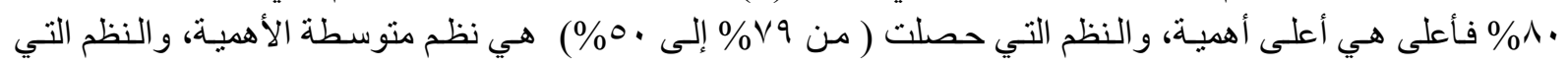

\begin{tabular}{|c|c|}
\hline \multirow{3}{*}{ أعلى أهمية } & أنظمة إطفاء الحريق \\
\hline & وكاميرات المر اقبة الذكية \\
\hline & أجهزة ذكية متصلة بالخدمات الإدارية \\
\hline \multirow{5}{*}{ متوسط الأهمية } & أنظمة التحكم بالإضاءة العامة \\
\hline & أنظمة توفير تجهيز ات مولدة للطاقة \\
\hline & توفير أنظمة لذوي الإحتباجات \\
\hline & توفير أنظمة لجمع المخلفات الصلبة \\
\hline & نظم التحكم بالطاقة الكترونيا \\
\hline أقلّ أهمبة & تغطية الفراغات بشبكات الإنترنت \\
\hline
\end{tabular}

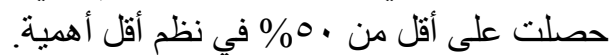
جدول (ז) أهمية النظم الذكية من وجهة نظر السكان

وقد اقترح السكان بالاستمار ات بعض الاقتر احات نوجز ها فيما يلي:

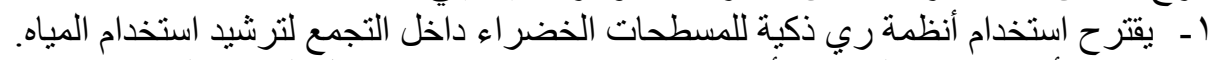

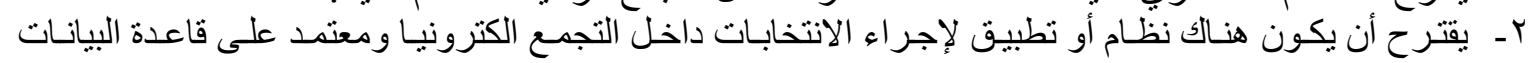
الموجودة بإدارة التجمع. r- يقترح إمكانية دفع مستحقات الصيانة داخل التجمع الكترونيا اعتمادا على قاعدة البيانات. 


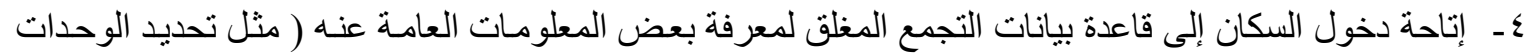
الساكنة والثاغرة) مع الاحتفاظ بسرية البيانات الثخان الثخية للسكان.

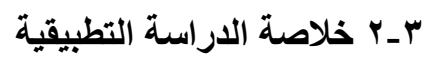

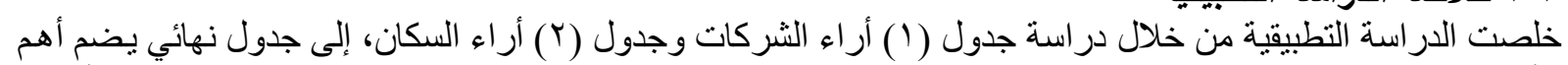

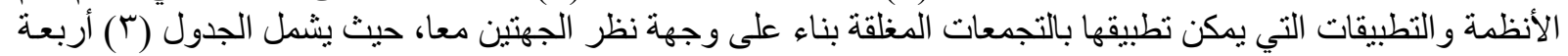

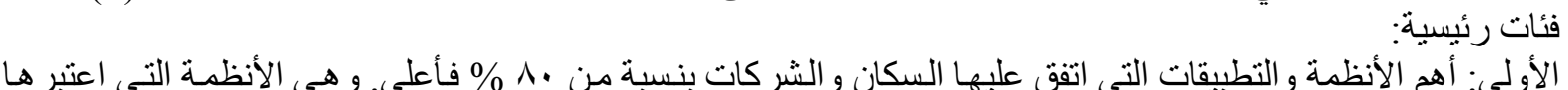

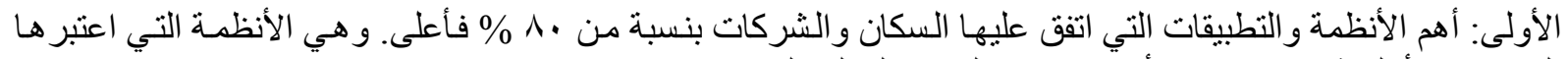

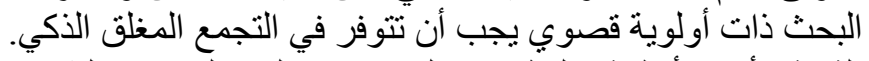

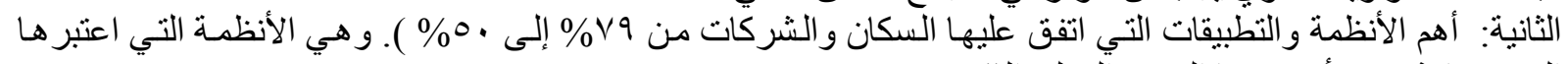

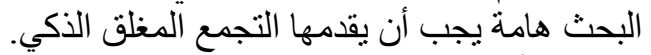

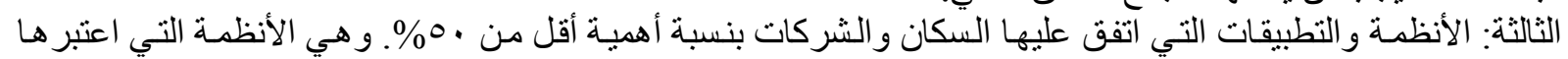

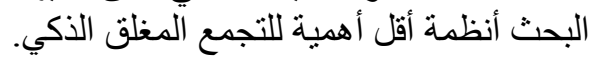

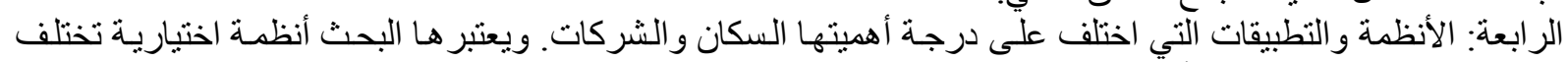
جدول (๕) أهمية النظم الذكية المستتجة باختلاف توجهات الانظة وكات وأراء السكان.

\begin{tabular}{|c|c|}
\hline أولوية قصوى & أنظمة إطفاء الحريق المبة الذكة \\
\hline \multirow{2}{*}{ هامة } & توفير أنظمة لذوي الإحتباجات \\
\hline & أنظمة التحكم بالإضاءة العامة \\
\hline أقلّل أهمية & تغطية الفر اغات بشبكات الإنترنت \\
\hline \multirow{4}{*}{ اختيارية } & أجهزة ذكية متصلة بالخدمات الإدارية \\
\hline & توفير أنظمة لجمع المخلفات الصلبة \\
\hline & نظم التحكم بالطاقة الكترونبا \\
\hline & أنظمة توفير تجهيز ات مولدة للطاقة \\
\hline
\end{tabular}

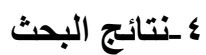

بناءا على الدر استة النظرية و التطبيقية للبحث يمكن استنتاج ما يلي:

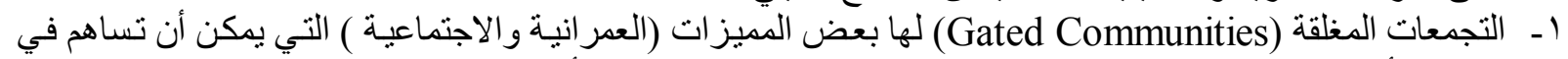

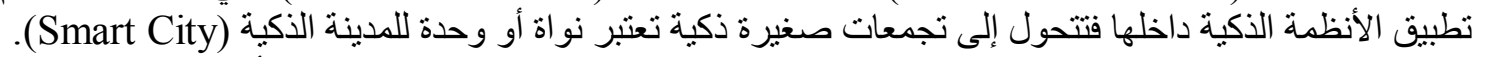

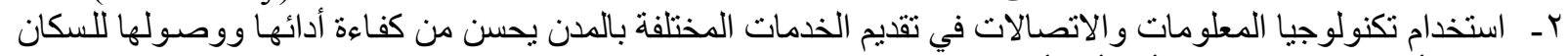
بشكل أسرع، بالإضافة إلى أنها أحد أدوات الحئ الحفاظ على البيئة حيث يمكنها التحكم في استهلاك الطاقة و المياه و التعامل

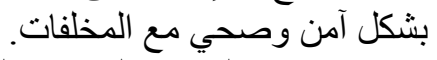

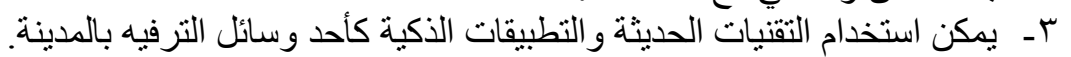

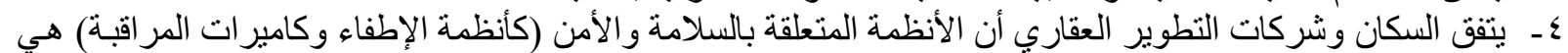

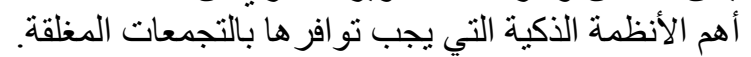

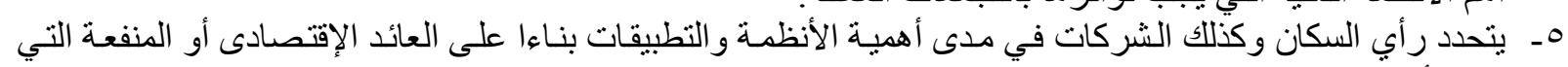
يمكن أن تعود على كل منهما من تطبيق هذا النظام.

\section{هـالتوصيات}

بطر ح البحث من خلال الدر اسة بعض التونة التوصيات:

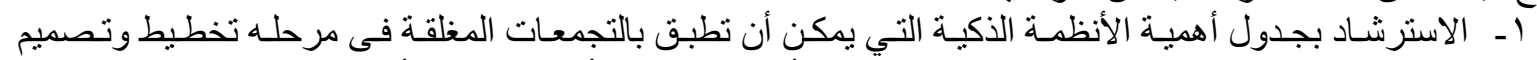

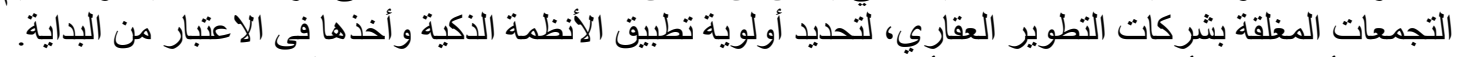

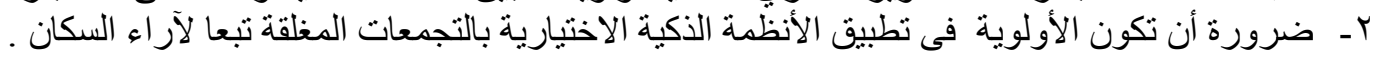

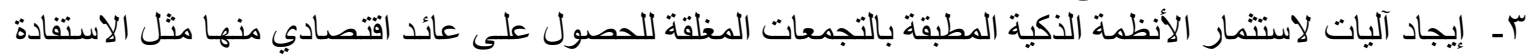

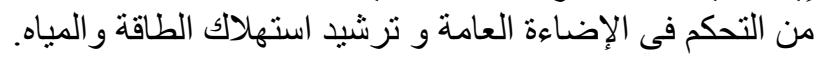

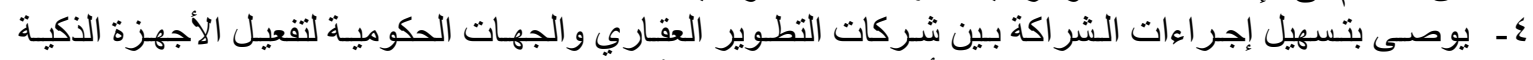

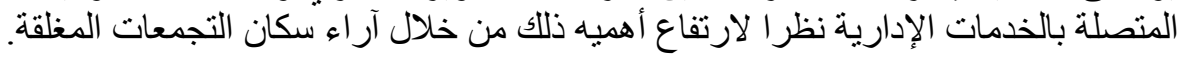




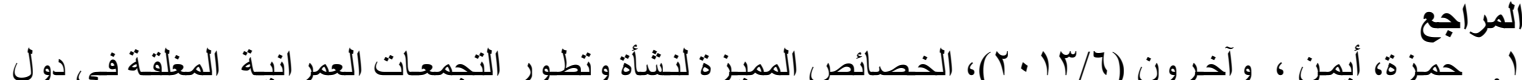

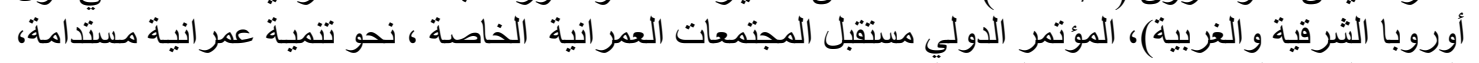
المركز القومي لبحوث الإسكان و البناء، التقاهرة.

2. Tim Heath, Taner Oc, \& others, 2011, Public Places - Urban Spaces, the dimensions of urban design, Architectural Press is an imprint of Elsevier.

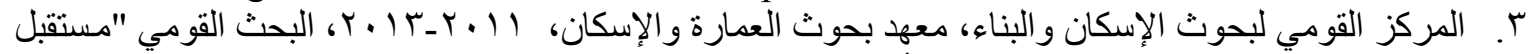

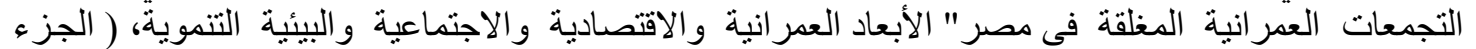

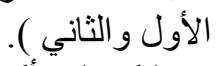

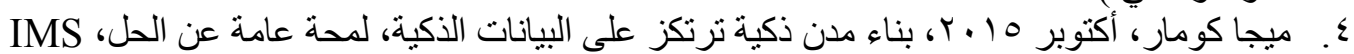

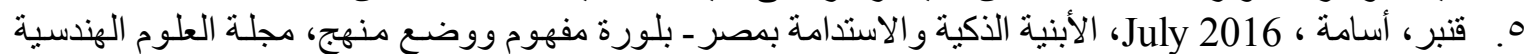

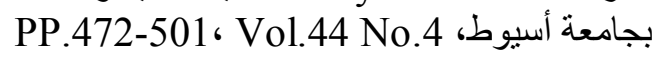

7. شلبي ، هايدي، April 2013 ، التأثثر البصري لنثورة المعلومات والاتصالات على الفراغات العمر انية، مجلة

جامعة الأز هر الهندسية،

7. Elmustafa sayed ali ahmed \& others, WSN 67(2) (2017) 126-148, EISSN 2392-2192, Internet of Things Applications, Challenges and Related Future Technologies, Www.worldscientificnews.com.

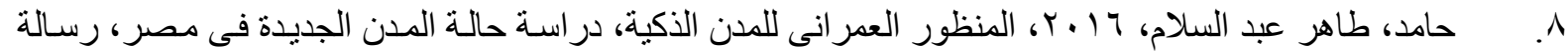

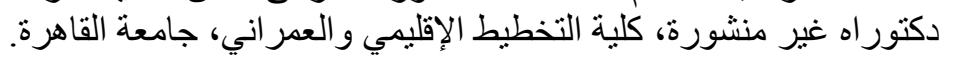

9. E-cube Labs Company, an innovative green technology for waste management in smart cities 'www.ecubelabs.com, 